\title{
Strategies to enhance nanoparticle-endothelial interactions under flow
}

\author{
Iwona Cicha* \\ Cardiovascular Nanomedicine Unit, Section of Experimental Oncology and Nanomedicine (SEON), \\ ENT-Department, University Hospital Erlangen, Erlangen, Germany
}

\begin{abstract}
Recent years have brought about substantial advances in nanomedical approaches to human diseases. Novel therapeutic and diagnostic nanoparticulate agents can be delivered via several routes, including enteral, transdermal, inhalational, as well as parenteral application. For nanoparticles administered via intravascular route, endothelial cells represent the firstcontact cells and their responses to the candidate nanosystems should be considered before clinical applications. Additionally, a number of drug-delivery nanosystems that target endothelium are currently proposed. It is increasingly evident that the future progress in the treatment of many human maladies, including cardiovascular diseases and cancer, will be closely bound with the development of endothelium-targeting nanosystems. As endothelial cells in circulation are constantly exposed to shear stress, investigating nanoparticle-endothelial interactions under flow conditions is necessary to estimate the cell responses in physiological-like settings. This mini-review focuses on the recently reported studies assessing the uptake of circulating nanoparticles and their biological effects on endothelial cells, and summarizes the targeting approaches to enhance endothelial internalization of nanoparticles under flow conditions.
\end{abstract}

Keywords: Endothelial cells, shear stress, nanoparticle internalization, targeted nanosystems, drug delivery, flow conditions

\section{Introduction}

Nanoparticles represent a versatile platform, adjustable for therapy and diagnostics of various human diseases. Although multiple delivery routes are possible, the majority of the clinically-relevant nanocarriers, such as anti-cancer and anti-inflammatory nano-drugs, are expected to require intravascular administration. For this purpose, a rational design of drug carriers is necessary to limit their cyto- and genotoxicity, prevent their clearance by reticuloendothelial system (RES) thus increasing the circulation half-life of their cargo, and to deliver a sufficient payload of therapeutics to the diseased regions. Ongoing efforts address these key issues in nanoparticle development, as the previous generations of injectable nanocarriers have often been plagued by suboptimal efficacy, as a result of rapid clearance by the RES [1], or an overall inability to reach the designated target in effective dosage [2-4].

Among the materials most commonly used for the synthesis of intravascular drug delivery systems are the nanoparticles or nanoshells made of natural or synthetic polymers, such as liposomes, dextrans, poly(lactic-co-glycolic acid) (PLGA), polyaccrylates, as well as metal or metal oxide nanoparticles (e.g. gold, silver, superparamagnetic iron oxide nanoparticles (SPIONs)), and quantum dots. Several of the commonly reported drug-carrier systems (reviewed in detail in [5]) are briefly outlined below.

\footnotetext{
*Corresponding author: Dr. Iwona Cicha, Section of Experimental Oncology and Nanomedicine (SEON), Glückstr. 10a, 91054 Erlangen, Germany. Tel.: +49 913185 43953; Fax: +49 913185 34828; E-mails: Iwona.Cicha@yahoo.com, Iwona.Cicha@uk-erlangen.de.
} 
Liposomes are composed of a lipid bilayer consisting of amphipathic phospholipids (primarily phosphatidylcholine) that enclose an interior aqueous space [6]. Being synthesized from naturally occurring phospholipids, liposomes have relatively low toxicity [6,7], but are easily cleared from the circulation by RES. The stability and circulation time of liposomal formulations can be greatly improved by conjugation of the head groups of phospholipids with polymerizable moieties (e.g. polyethylene glycol (PEG)). Liposomes are often functionalized with maleimide, which allows conjugation of antibodies or other targeting ligands [8]. Among their advantages as a drug delivery platform are the ease of preparation, commercial availability and overall low immunogenicity [9], which is expected to enable safe and repeated administration. However, the effects of shear forces on the liposomal bilayer integrity are largely unknown. Thus far, a PEGylated liposomal formulation of doxorubicin (Doxil ${ }^{\circledR}$ ) has been the first FDA-approved nanodrug indicated for the treatment of several types of cancer, including AIDSrelated Kaposi's sarcoma, recurrent ovarian cancer, metastatic breast cancer and multiple myeloma (reviewed in [10]).

PLGA is the most common biodegradable polymer approved for use in humans, frequently used in form of nanoshells or nanocarriers. The favourable safety profile of PLGA results from its physiological degradation to easily metabolized products, namely lactic acid and glycolic acid [11]. In animal models, PLGA nanoparticles have been tested as drug carriers for tissue plasminogen activator (mouse model of thrombosis [12]), pitavastatin (rat model of myocardial ischemia-reperfusion [13]), superoxide dismutase (mouse model of stroke [14]), as well as carriers of several anti-cancer agents [11, 15].

Gold nanoparticles consisting of a dielectric core of silica coated with a metallic layer of gold, are tunable to various sizes and forms [16] and can be used for e.g. for optical imaging, or photothermal ablation therapy, as well as biosensors, or drug carriers. Gold nanoparticles have been utilized for experimental delivery of anti-cancer agents [17-19] and for delivery of inotropic agent (levosimendan) in a rat model of heart failure [20]. However, the important concern related to gold particles is their potential cytotoxicity and a slow elimination resulting in a long-term persistence within many organ systems.

SPIONs consist of iron oxide core, often coated with organic materials such as fatty acids, polysaccharides, or polymers [21, 22]. The magnetic properties of SPIONs allow the remote control of their accumulation by means of external magnetic field [23], as well as their application for hyperthermiatherapy of cancer [24]. However, in contrast to their broad utility as imaging agents [25-29], relatively few reports addressed the use of SPIONs for vascular drug delivery thus far [30, 31].

Notably, the above-described materials can be freely combined in order to achieve the desired characteristics of the nanoparticles, e.g. biocompatibility or contrast enhancement. Such hybrid nanosystems with adjustable characteristics are expected to improve the future clinical utility and safety of nanotherapies. Still, the successful development of novel intravascular nanosystems for disease-specific imaging and drug delivery requires extensive studies in vitro and in vivo. Apart from considering the disease mechanisms and pathological processes, these novel therapeutic approaches would greatly benefit also from the knowledge of endothelial biology and endothelial transport mechanisms to ensure adequate safety and effective drug delivery, thus increasing therapeutic success of intravascular nanosystems.

\section{Endothelial functions in health and disease}

In the mammalian body, the circulating blood is separated from the surrounding tissues by a biological barrier consisting of endothelial cell monolayer. The endothelium, an expansive cell monolayer covering a total surface area of 4000-7000 $\mathrm{m}^{2}$ in an average-sized human [32], is a highly metabolically active organ. Apart from fulfilling the barrier function, endothelial cells are involved in many physiological processes, including the control of vasomotor tone, leukocyte adhesion and trafficking, 
thrombocyte adhesion and hemostasis. In response to inflammation and injury, endothelial barrier function in microvessels is reduced: Increased capillary permeability allows the migration of immune cells into the diseased or injured tissues, in order to protect the tissues from harmful pathogens, damaged cells or irritants [33]. In the medium and large arteries, however, increased vascular permeability may play a deleterious role, contributing to the formation of atherosclerotic plaques, which are initiated by the subendothelial accumulation of blood lipids and inflammatory cells.

Oxygen and nutrients supply is maintained in almost all tissue types by a vast network of blood capillaries distributed not further apart than the diffusion limit of oxygen, which is $200 \mu \mathrm{m}$ [34]. In tumours, wounds, or atherosclerotic plaques alike, hypoxia is thus a driving stimulus for angiogenesis. Without blood vessels, the neo-plasms and neo-tissues cannot grow beyond a critical size.

In physiological angiogenesis, increased microvessel permeability and matrix degradation are followed by endothelial cell migration and proliferation $[35,36]$. The resulting thin-walled, permeable sprouts undergo a tightly-regulated maturation process, involving the basement membrane formation and pericyte recruitment. Sprouting from the pre-existing vessels is also the main route for tumor angiogenesis which, however, lacks the coordinated temporal and spatial regulation, leading to structural and functional abnormalities and vessel immaturity. In contrast to normal vascular network, tumour vessels are tortuous and unevenly dilated, with excessive branches and shunts [35]. These vessels are also leaky with numerous endothelial fenestrae, vesicles and transcellular holes and widened intercellular junctions. The basement membrane is discontinuous or absent, and the mural cells are missing. Similar observations have been reported for atherosclerotic plaque neovasculature, where intraplaque microvascular endothelial cells showed numerous abnormalities, such as membrane blebs, intracytoplasmic vacuoles, open intercellular junctions, and basement membrane detachment [37]. This compromised structural integrity of the intraplaque microvessels can lead to enhanced leukocyte infiltration, leakage and hemorrhage [38, 39].

In terms of the therapeutic approaches, the immaturity of the tumor or plaque neovessels improves the chances of efficient drug delivery [36]. For example, without a microvascular network, the delivery of anti-cancer drugs in effective quantities to the center of the tumour would not be possible. Moreover, the capillary leakage improves the possibility of drug accumulation in the tumor, as the compromised endothelial barrier results in leaky vessels with intercellular gap sizes of $100 \mathrm{~nm}$ to $2 \mu \mathrm{m}$ depending on the tumor type [40-42]. Additionally, tumors lack a proper lymphatic drainage system, which results in an increased interstitial pressure at the center of tumors relative of the tumor periphery [43]. Therefore, drugs and nanoparticles that cross blood-tumor tissue barrier have higher retention times than in normal tissues. This combination of leaky vasculature and poor lymphatic drainage results in so-called Enhanced Permeation and Retention (EPR) effect [44], so that the nanoparticles which enter the interstitium via immature vessels can be entrapped in the tumor $[43,45]$.

\section{Intravascular drug delivery strategies}

In order to design safe carriers, thorough preclinical analyses of the candidate nanosystems intended for intravascular administration are necessary, including their basic physicochemical characterization and the biological effects of nanoparticles on the vascular cells and blood components. Furthermore, it is important to consider the effects of hemodynamic forces on nanoparticle behaviour in circulation and adhesion to the endothelium.

To date, two main strategies are proposed to deliver nanocarriers to the vascular wall, including passive and active targeting. The former approach exploits the enhanced permeability of the endothelium, particularly in inflammatory diseases and cancer, where the extravasation of nano-sized particles is facilitated [44]. Nanoparticles that prolong the circulation half-life of the carried drugs are therefore 
expected to increase the payload of drugs reaching the target site. Passive targeting can also utilize nanoparticle properties, in particular cationic charge [46], to increase non-specific cell targeting of negatively-charged endothelial glycocalyx [47-50]. However, despite the presence of leaky vessels in tumors and the compromised blood-brain barrier in many brain disorders, the efficacy of drugs and passively-targeted drug carriers applied via intravenous route is often insufficient for a meaningful clinical improvement. In parallel, increasing the systemic dose in attempt of achieving the sufficient drug efficacy is often impossible due to numerous adverse effects. For this reason, nanoparticulate carriers that can be functionalized for actively-targeted drug delivery [8] constitute an attractive alternative for therapy of e.g. cancer or neurodegenerative diseases [18].

The active targeting of nanoparticles to vascular wall is achieved by grafting the surface or the shell of the nanocarriers with specific ligands or antibodies to molecules expressed on the endothelium. This targeting approach has been shown to allow a better control of nanoparticle biodistribution and to enhance their therapeutic efficacy (see below). Depending on the disease context, various endotheliumexpressed molecules have been tested as targets for nanoparticles, including vascular endothelial growth factor receptors [51, 52] and integrins [53, 54] in cancer (reviewed in [44]) as well as adhesion molecules in inflammation and atherosclerosis (reviewed in [55]), as also discussed in a dedicated chapter below.

Another promising strategy of drug delivery, which results in increased drug payloads in the target tissue, at the same time reducing their systemic dose and toxicity, is based on so-called "magnetic drug targeting". In this approach, conjugation of superparamagnetic particles with drugs, in combination with an external magnetic field is used to target the nanoparticles to the diseased vasculature regions as demonstrated by the studies in a rabbit model of cancer [56-58], a mouse model of thrombosis [59], a mouse model of cardiac ischemia [60] and several mouse models of cancer [61-63].

\section{Regulation of endothelial function and nanoparticle interactions by the flow patterns}

The specific hemodynamic conditions characteristic of the target vasculature region are expected to modulate the particle internalization and therapeutic efficacy. The wall shear stress in humans varies between $0.5-6 \mathrm{dyn} / \mathrm{cm}^{2}$ in the veins, $3-7 \mathrm{dyn} / \mathrm{cm}^{2}$ in the peripheral arteries (e.g. the brachial or femoral artery), and $10-15 \mathrm{dyn} / \mathrm{cm}^{2}$ in the central arteries (e.g. the carotid artery) [64]. In terms of nanocarriermediated drug delivery to microvasculature (e.g. pulmonary circulation), the hemodynamic forces may be of lesser relevance, as the single file flow in microvessels and capillaries [65] increases the contacts of nanoparticles with the vessel wall. However, the interactions and binding dynamics of drug carriers targeted to the endothelium in medium and large-diameter arteries may, apart from inflammatory status [66], largely depend also on local hemodynamics and blood rheology that govern both the endothelial responsiveness and the behavior of blood-borne cells and particles, as briefly discussed below.

In the arteries, the signaling pathways activated by laminar shear stress (including ion channels, $\mathrm{G}$ proteins, growth factor receptors, tyrosine kinase receptors, integrins, caveolae, and the cytoskeleton components (reviewed in $[67,68]$, see Fig. 1), exert a profound anti-apoptotic effect on endothelial cells [69-71], and prevent cytokine-induced expression of pro-inflammatory genes and endothelial adhesion molecules [72-74]. Moreover, endothelial glycocalyx thickness strongly depends on the shear stress patterns. Laminar shear stress promotes glycocalyx formation in ECs [75-77] and thick and negatively charged endothelial glycocalyx improves the barrier function $[78,79]$. In contrast, the exposure to disturbed, non-uniform shear stress renders endothelial cells prone to inflammatory activation, and increases the permeability of monolayer to immune cells and blood components [74, 80-82]. Additionally, upon exposure to non-uniform shear stress, the glycocalyx becomes stiffer and loses its buffering function [75-77], thus further increasing the endothelial permeability [83]. Therefore, shear stress-activated intracellular processes may represent the major modulators of the nanoparticle 


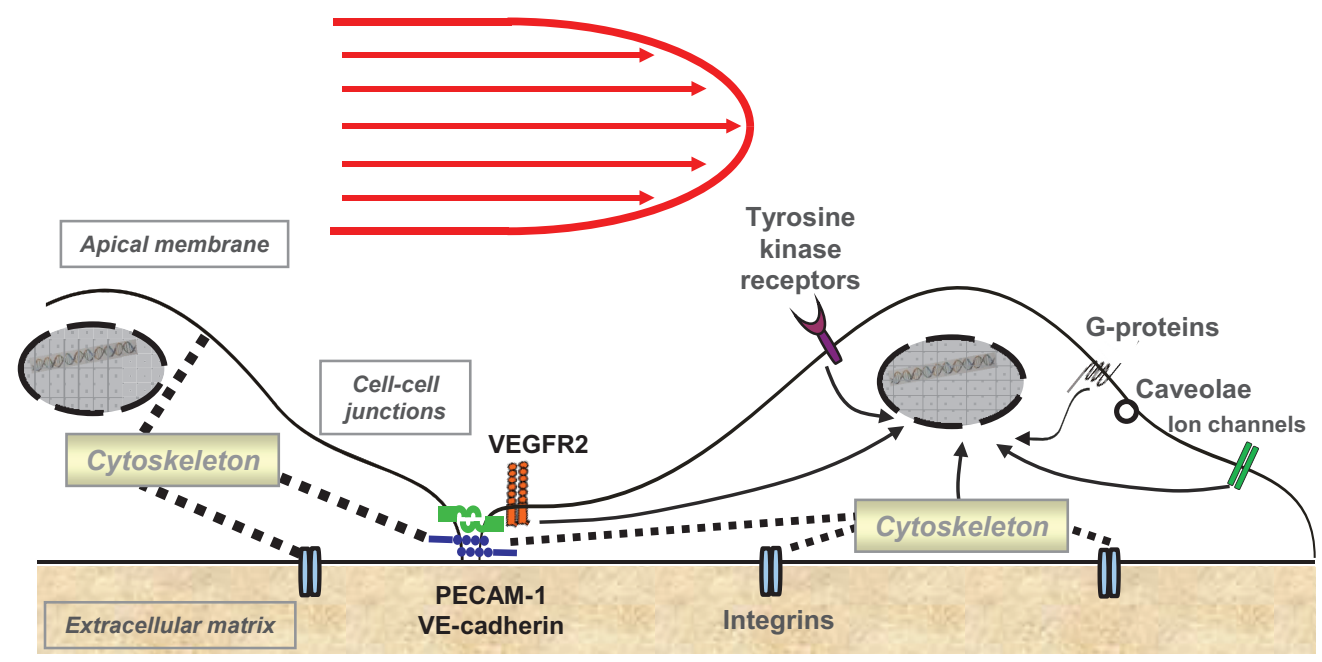

Fig. 1. Shear stress-activated signalling pathways in endothelial cells. PECAM-1, platelet-endothelial cell adhesion molecule 1; VE-cadherin, vascular endothelial cadherin, VEGFR2, vascular endothelial growth factor 2.

internalization by arterial endothelial cells. Moreover, due to the larger size of the vessels, the rheological behavior of blood cells in the arterial flow differs from that in the microvessels [84-86]. Erythrocyte accumulation in the center of the lumen and the formation of rouleaux, leaving a cell-free layer at the vessel wall, may strongly affect the margination of nano-sized particles [87].

\section{Nanoparticle internalization under flow conditions}

Although endothelial cells represent the first-contact cells for nanoparticles administered via intravascular route and are often the key target for therapeutic nanocarriers, relatively few studies have investigated nanoparticle-endothelial interactions under flow conditions, which is a pre-requisite to estimate the cellular responses in physiological-like settings. In terms of nanoparticle applicability in certain diseases (e.g. atherosclerosis), this can critically affect the efficacy of the drug delivery systems or contrast agents accumulation in the diseased regions in vivo. The majority of the existing studies, however, utilize static cell culture conditions to assess the endothelial toxicity of nanoformulations and their cellular interactions. Below, several recent attempts to investigate the influence of shear stress on the uptake of circulating nanoparticles and their effects on endothelial cells in vitro and in vivo are discussed.

From the existing reports, it is clear that the effects of shear stress on the particle uptake is to a large degree dependent on the particle type and the experimental settings, including the selected shear stress magnitude and the exposure time. Samuel et al. [88] compared the short-term effects of shear stress $\left(0,0.5,1\right.$, and $\left.5 \mathrm{dyn} / \mathrm{cm}^{2}\right)$ on the interactions of negatively charged, thioglycolic acid-coated $2.7 \mathrm{~nm}$ and $4.7 \mathrm{~nm}$ CdTe quantum dots (QD) and $50 \mathrm{~nm}$ silica nanoparticles (NP50) with HUVECs using a microfluidic platform (channel dimensions: $600 \mu \mathrm{m}$ width $\times 120 \mu \mathrm{m}$ height $\times 20 \mathrm{~mm}$ length). Cell monolayers were exposed to $3 \mu \mathrm{M}$ negatively charged QD2.7 (2.7 nm), QD4.7 (4.7 nm), or NP50 $(50 \mathrm{~nm})$ suspended in PBS for 20 minutes. NP50 did not enter the cytoplasm of cells grown either in static or flow conditions, but were bound to the cell membranes under flow conditions. In contrast, QDs did not show internalization within 20 min under static conditions, but penetrated the endothelial cell cytoplasm and localized near the nucleus under flow conditions [88]. The maximal uptake of QDs was observed at $0.5 \mathrm{dyn} / \mathrm{cm}^{2}$, with a decrease at $5 \mathrm{dyn} / \mathrm{cm}^{2}$, and was associated with shear stress-induced 
cytoskeleton reorganization and formation of membrane ruffles, as described for the acute endothelial response to shear stress exposure [89-91]. The cytotoxicity studies carried in static conditions, however, stand in a contradiction with the data on QD4.7 particle uptake: Whereas no uptake was observed within the first $20 \mathrm{~min}$, a significant reduction of in the number of treated cells was detected, indicating a significant toxicity [88], which is unlikely to occur in the absence of particle internalization. Regretfully, neither the consequences of the exposure to QDs under flow conditions on cell viability, nor the effects of prolonged exposure under flow on particle internalization and their cytotoxicity were reported. However, the presented results of long-term static exposure indicate, that although QD are not taken up within the first 20 min of exposure, they must be internalized by endothelial cells also in static conditions upon prolonged incubation: Whereas NP50 did not cause any cytotoxic effect on cultured HUVECs even after $24 \mathrm{~h}$ of exposure, a significant reduction in the number of treated cells was observed at all time points (i.e, 0.3, 4, 8, and $24 \mathrm{~h}$ ) after the QD4.7 treatment. QD2.7 were well tolerated for up to $4 \mathrm{~h}$, followed by a significant decrease in the number of cells at 8 and $24 \mathrm{~h}$, indicating a slower kinetics of particle internalization [88]. Furthermore, it must be noted, that the presented data were obtained on not fully confluent cells, which may affect both the cell behavior and interactions with nanoparticles.

A different approach in vitro was applied by Rinkenauer et al. [92], who utilized a chip-based dynamic cell culture model to pre-expose endothelial cells to different levels of shear stress prior to the incubation with nanoparticles. This model was compared with the static cell culture and a mouse model, in order to assess its capability to predict the in vivo responses to the methacrylate-based nanoparticles. Three types of polymeric nanoparticles of similar size were compared: Negatively charged poly ((methyl methacrylate)-co-(methacrylic acid)) with 3\% methacrylic acid (3\% PMAA, $196 \mathrm{~nm},-43.3 \mathrm{mV})$, poly((methyl methacrylate)-co-(methacrylic acid)) with 13\% methacrylic acid (13\% PMAA, $205 \mathrm{~nm}$, $-38.3 \mathrm{mV})$, and poly((methyl methacrylate)-co-(2-dimethylamino ethyl-methacrylate)) with $20 \%$ 2-dimethylamino ethyl-methacrylate (20\% PDMAEMA, $207 \mathrm{~nm},+31.3 \mathrm{mV})$, representing polymers with $\mathrm{pH}$-dependent anionic and cationic charges [92]. HUVECs seeded in rhombic chamber chips ( $120 \mu \mathrm{L}$ chamber volume) were exposed to shear stress for $24 \mathrm{~h}$, followed by 60 min perfusion with nanoparticles at a concentration of $200 \mu \mathrm{g} / \mathrm{mL}$. Shear stress values of $0.7,3.0,6.0$ and $10.0 \mathrm{dyn} / \mathrm{cm}^{2}$ were selected, representing basal nutrient exchange flow with minimal mechanical stimulation observed e.g., in liver sinusoidal vessels $\left(0.7 \mathrm{dyn} / \mathrm{cm}^{2}\right)$ and the shear stress values observed in human circulation. Different effects of shear stress on particle internalization were observed, whereby the low-charged particles (3\% PMAA) showed the minimal uptake, with no major differences between static versus flow conditions. A slight increase in the amount of internalized nanoparticles was observed in cells exposed to $10.0 \mathrm{dyn} / \mathrm{cm}^{2}$, but it was not statistically significant [92]. The dynamic cell culture at shear stresses of $3 \mathrm{dyn} / \mathrm{cm}^{2}$ and higher enhanced the uptake of $13 \%$ PMAA particles in a shear stress-dependent manner. Interestingly however, whereas under static conditions 20\% PDMAEMA showed the highest uptake, the internalization of these cationic particles was decreased under flow conditions, without a clear shear-stress dependent pattern. In vivo, all tested nanoparticles were mainly cleared by Kupffer cells in the liver, but they were also internalized by the liver-specific endothelial cells to a lesser extent. Similar to the in vitro results, the estimated uptake of 3\% PMAA was markedly lower that other particle types, whereas the uptake of 13\% PMAA was somewhat lower than 20\% PDMAEMA [92].

In a recent study, Fede et al. [93] compared the effects of gold nanoparticles stabilized with sodium citrate on human umbilical vein endothelial cells cultured in static conditions versus cells grown a single-channel microfluidic device (length $4 \mathrm{~cm}$, width $2 \mathrm{~mm}$ and height $150 \mu \mathrm{m}$ ) and continuously perfused with nanoparticle suspensions. The authors utilized laminar flow at $30 \mu \mathrm{L} / \mathrm{min}$, corresponding to about $0.5 \mathrm{dyn} / \mathrm{cm}^{2}$ and at $5 \mu \mathrm{L} / \mathrm{min}\left(0.1 \mathrm{dyn} / \mathrm{cm}^{2}\right)$. Despite these relatively low shear stress values, significant differences were observed in gold nanoparticle accumulation after $24 \mathrm{~h}$ exposure in cells grown under flow versus static conditions. Under shear stress of $0.1 \mathrm{dyn} / \mathrm{cm}^{2}$, the number of nanoparticles per cell was lower by an order of magnitude than in static conditions $\left(2.6 \times 10^{5}\right.$ 
versus $2.9 \times 10^{6}$ nanoparticles per cell, respectively). Consequently, the viability of HUVECs exposed to gold nanoparticles in static conditions was significantly reduced at concentrations higher than $5 \times 10^{10}$ nanoparticles $/ \mathrm{mL}$ (gold concentration $1.6 \times 10^{-3} \mathrm{mg} / \mathrm{mL}$ ), whereas under flow conditions $\left(0.1 \mathrm{dyn} / \mathrm{cm}^{2}\right)$, the fraction of viable cells was approximately $20 \%$ higher at $5 \times 10^{11}$ nanoparticles $/ \mathrm{mL}$, and $1 \times 10^{12}$ nanoparticles/mL [93].

Similar results were obtained in our recent studies utilizing the bifurcating flow channels to compare the nanoparticle toxicity on endothelial cells exposed to laminar shear stress $\left(10 \mathrm{dyn} / \mathrm{cm}^{2}\right)$ or nonuniform shear stress (spatial range $0.6-5 \mathrm{dyn} / \mathrm{cm}^{2}$ ) [94]. The HUVEC monolayers were perfused for $18 \mathrm{~h}$ with medium containing 100 or $400 \mu \mathrm{g} / \mathrm{mL}$ of different types of nanoparticles, including two types of liposomes, lipid nanoparticles of 3 different sizes, 2 types of polyaccrylate particles and 2 types of iron oxide nanoparticles. Both the liposomes and the dextran T6-coated iron oxide nanoparticles showed excellent biocompatibility at static and flow conditions. All lipid nanoparticles, as well as iron oxide nanoparticles coated with lauric acid and albumin, reduced endothelial viability at about $100 \mu \mathrm{g} / \mathrm{mL}$ in static conditions. In contrast, these particles were well tolerated by the cells exposed to flow up to $400 \mu \mathrm{g} / \mathrm{mL}$, and did not affect endothelial cell morphology, nor induced cell detachment due to shear stress exposure. In the case of poly(isobutylcyanoacrylate) nanoparticles coated with 90\% carboxymethyl-dextran and 10\% fucoidan, cytotoxic effect was induced from the concentration of $50 \mu \mathrm{g} / \mathrm{mL}$ in static conditions. However, these nanoparticles at $100 \mu \mathrm{g} / \mathrm{mL}$ did not dramatically affect endothelial viability under flow, the cytotoxic effect being observed in the laminar and nonuniform shear stress region at very high concentrations $(400 \mu \mathrm{g} / \mathrm{mL})$. Only for one nanoparticle type (poly(isobutylcyanoacrylate) nanoparticles coated with $80 \%$ dextran T70, 10\% diethylaminoethyldextran and $10 \%$ fucoidan), the concentrations affecting cell growth and viability in static conditions $(100 \mu \mathrm{g} / \mathrm{mL})$ also induced cell death under flow conditions [94]. This may be related to the fact that these particles are positively-charged, relatively large $(245 \mathrm{~nm})$ and characterized furthermore by a tendency to aggregate. These features may contribute to an increased endothelial uptake even under high shear stress conditions, negatively affecting endothelial viability at concentrations of $100 \mu \mathrm{g} / \mathrm{mL}$ and higher. Collectively, our data indicated that in case of many types of nanoparticles, the longer-term cell culture assays under static conditions may overestimate the potential toxicity. This results from the inherent property of nanoparticles, namely their sedimentation, which occurs over time and leads to increased effective concentrations of nanoparticles in the nearest vicinity of cell monolayer. As shown in our studies, this effect was responsible for the majority, but not all, of the cytostatic and cytotoxic effects observed after $24 \mathrm{~h}$ incubation below the concentrations of $200 \mu \mathrm{g} / \mathrm{mL}$ [94].

Regarding the existing reports, it is acutely clear that no meaningful comparisons of the obtained results are possible, as each group utilizes different flow models with differing shear stress magnitudes and durations. To be able to draw conclusions about the effect of physiologic shear stress on nanoparticle internalization, comprehensive standardised studies are necessary that would compare the effects of a broad range of shear stress levels (low vs high), patterns (uniform vs non-uniform) and duration (acute vs chronic) on the particle uptake by endothelial cells in these conditions.

\section{Whole blood models}

Prior work demonstrated that platelets accumulate within the cell free layer near the vessel walls [95, 96], and that the near-wall concentration of platelet-sized latex beads ( $2.38 \mu \mathrm{m}$ diameter) in flowing blood suspensions can be even 3 -fold greater than in the central region of the flow [97]. Mathematical studies reported by Lee et al. suggested that compared with spherical particles, elongated particles exhibit larger propensity to laterally drift and marginate in laminar flow and that ellipsoidal micrometersized particles display stronger hydrodynamic margination under flow than sub-micrometer and 
nanometer particles [98]. From this model, the minimum equivalent radii for observing margination under normal hemodynamic conditions (i.e. shear rate of $10^{3} / \mathrm{s}$ ) with no external forces would be $7 \mu \mathrm{m}$ for silica, $3.5 \mu \mathrm{m}$ for iron oxide and $2 \mu \mathrm{m}$ for gold particles. Considering silica particles of $500 \mathrm{~nm}$ diameter, the modelled contributions of the inertial and gravitational forces under physiological conditions are negligibly small, preventing their margination. This effect is even more valid for lighter particles, such as polymeric or lipid-based beads. The model predicts that under pathological conditions, e.g. within the tumor microcirculation, the gravitational force may dominate leading to the sedimentation of larger particles in horizontal capillaries [98]. These mathematical predictions indicate that, in the absence of external forces, sub-micrometer and nanometer particles of any shape within the circulation can only oscillate around their trajectory. The above-discussed findings were to a large extent confirmed by a series of comprehensive ex vivo investigations concerning the endothelial interactions with nano- and microparticles suspended in human whole blood, reported by the group of Eniola-Adefeso $[99,100]$. These authors utilized spherical particles conjugated with sialyl Lewis ${ }^{\mathrm{a}}\left(\mathrm{sLe}^{\mathrm{a}}\right)$, a ligand specific to the endothelial-expressed selectins, with diameters ranging from $100 \mathrm{~nm}$ to $10 \mu \mathrm{m}$, showing that nanoparticles (100-500 $\mathrm{nm}$ ) displayed minimal margination from human blood flowing in chambers of varying heights $(125-700 \mathrm{~mm})$ towards endothelial monolayer. In contrast, a significantly higher binding of intermediately-sized microspheres $(2-5 \mu \mathrm{m})$ was detected in this model [99]. Notably, although microparticle attachment to the endothelium was 2 to 4 -fold increased under pulsatile blood flow compared to laminar flow, the margination of nanoparticles was not enhanced. In a further study [100], the authors investigated in detail the effects of geometrical parameters (volume, aspect ratio, axis length) on the margination efficacy of spherical and ellipsoid particles, showing that although margination of rodshaped microparticles with high aspect ratios was significantly improved as compared to spheres of equal volume, the nanorods did not display enhanced margination compared to that of nanospheres [100]. The authors concluded that both nanorods and nanospheres show no margination in the presence of erythrocytes in vitro, confirming the theoretical predictions of Lee et al. [98]. Thus far, however, the detailed studies which would verify these findings in animal models are missing, and the nanoparticle behavior under flow is expected to differ in dependence of inherent particle properties (size, shape, density, or stiffness) as well as blood rheological parameters, including shear rate, hematocrit, and erythrocyte aggregability [101]. Extensive in vivo investigations at all physiological ranges of shear stress and vessel diameter are thus urgently needed to characterize the ability of particles with different physicochemical properties to deliver drugs to the specific vascular beds.

\section{Strategies to enhance endothelial interactions with nanoparticles}

The above-discussed in vitro and ex vivo results indicate that many types of nanocarriers may not be adequate for vascular applications in medium and large human arteries due to their small size and/or insufficient margination from the bloodstream. Extensive efforts are therefore focused on identifying efficient targeting approaches that could enhance the binding of nanoparticles to vascular endothelium at the disease-specific regions, including medium and large vessels.

\subsection{Molecular targeting}

Conjugating nanoparticles to specific ligands that target endothelial activation markers may serve as a useful approach to enhance the internalization of particles under arterial flow (Fig. 2A). Several endothelial adhesion molecules have thus far been tested as molecular targets in vitro and in vivo, among them vascular cell adhesion molecule-1 (VCAM-1), intercellular adhesion molecule-1 (ICAM-1), platelet-endothelial cell adhesion molecule-1 (PECAM-1), as well as endothelial selectins. 


\section{A. Molecular targeting}

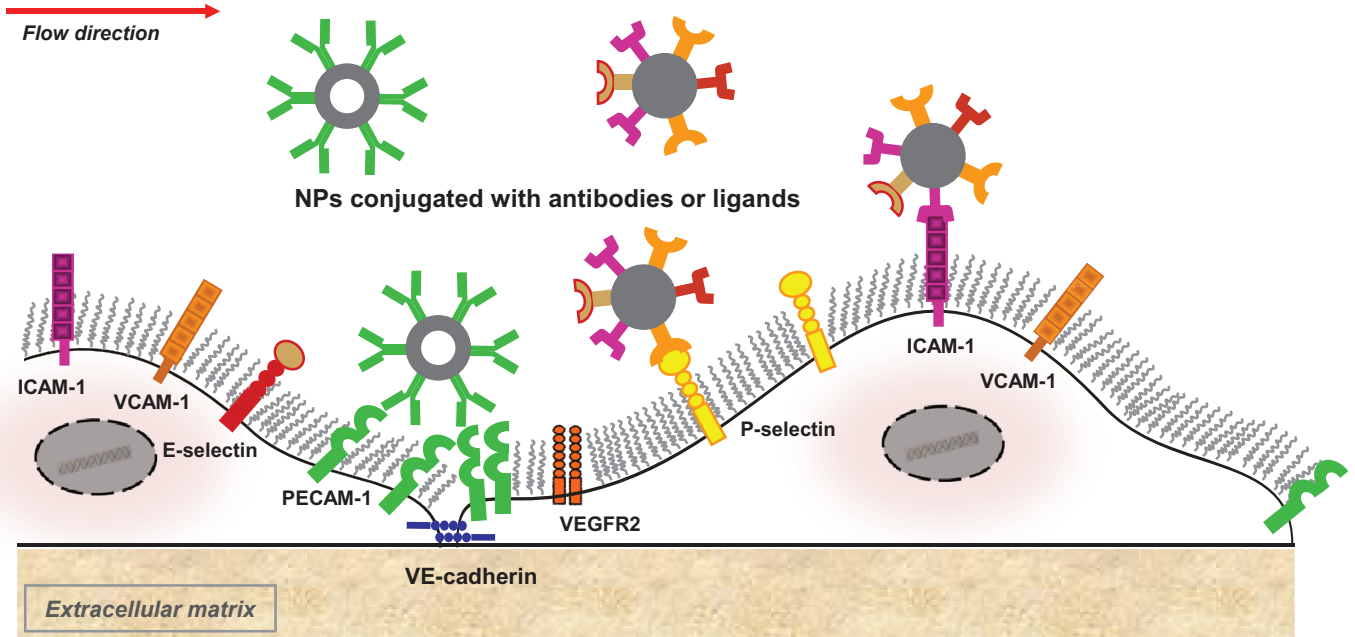

B. Magnetic targeting

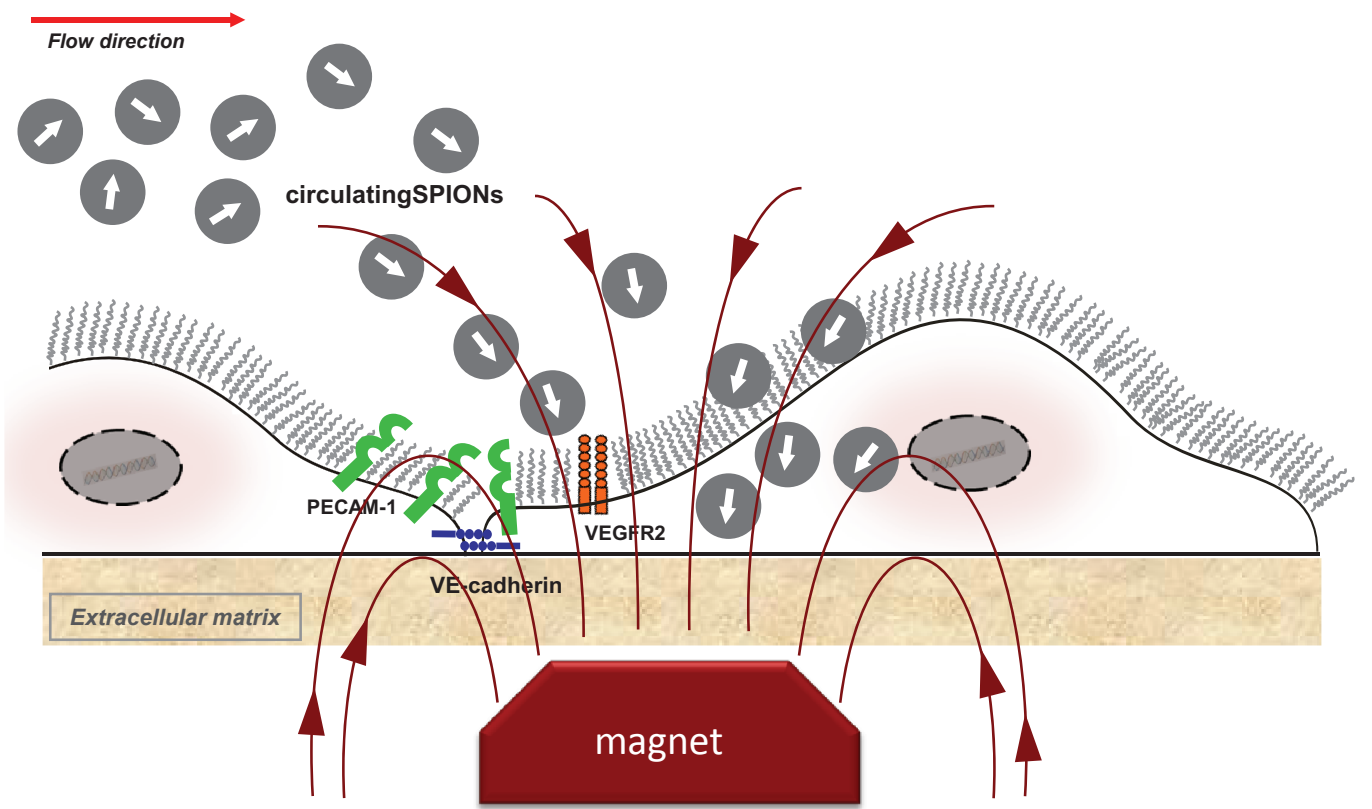

Fig. 2. Active targeting of nanoparticles to endothelial cells. (A) Molecular targeting; (B) Magnetic targeting. ICAM-1, intercellular adhesion molecule-1; NP, nanoparticles; PECAM-1, platelet-endothelial cell adhesion molecule 1; SPIONs, superparamagnetic iron oxide nanoparticles; VCAM-1, vascular cell adhesion molecule-1; VE-cadherin, vascular endothelial cadherin, VEGFR2, vascular endothelial growth factor 2.

Yang et al. $[102,103]$ investigated the influence of anti-VCAM antibodies on endothelial uptake of ultrasound microbubbles $(3.57 \mu \mathrm{m})$ and fluorescent core-shell $\mathrm{Fe}_{3} \mathrm{O}_{4} @ \mathrm{SiO}_{2}$ nanoparticles $(355 \mathrm{~nm})$ under short-term flow exposure in vitro. Targeted microbubble adhesion to LPS-activated endothelial cells increased dose-dependently with increasing surface antibody densities, but was 3-5 fold decreased in cells exposed to $10.4 \mathrm{dyn} / \mathrm{cm}^{2}$ for $3 \mathrm{~min}$ as compared to cells grown under lower shear stress $\left(6.3 \mathrm{dyn} / \mathrm{cm}^{2}\right)$ [102]. In the case of anti-VCAM-conjugated $\mathrm{Fe}_{3} \mathrm{O}_{4} @ \mathrm{SiO}_{2}$ nanoparticles, the 
degree of nanoparticle adhesion to activated HUVECs decreased significantly relative of static conditions when the cells were exposed to increasing shear stress levels $\left(1.1,5.15\right.$, and $\left.9.94 \mathrm{dyn} / \mathrm{cm}^{2}\right)$ for $3 \mathrm{~min}$. With increasing exposure time $(0,1,5,10 \mathrm{~min})$, the adhesion of nanoparticles to HUVEC monolayer at $5.15 \mathrm{dyn} / \mathrm{cm}^{2}$ was furthermore reduced. This pattern was observed for both non-targeted and VCAM-1-targeted nanoparticles, whereby the accumulation of VCAM-targeted nanoparticles was nearly 2-fold more effective under all tested conditions [103].

These studies are in agreement with the reported in vivo approaches to VCAM-1 targeting. As an example, Kelly et al. [104] utilized fluorescent iron oxide nanoparticles conjugated with a peptide containing sequence homology to the alpha-chain of very late antigen-4 (VLA-4, a known ligand for VCAM-1). These peptides showed 12-fold higher target-to-background ratios as compared with VCAM-1 monoclonal antibodies and successfully identified VCAM-1-expressing endothelial cells in a murine model of inflammation and in atherosclerotic lesions of apolipoprotein $\mathrm{E}$ (ApoE)-deficient mice [104], in contrast to control unconjugated nanoparticles which did not bind to endothelial cells. Conjugating nanoparticles to yet another peptide homologous to VLA-4, further increased their affinity to VCAM-1 in the aortic roots of ApoE-deficient mice [105]. In a recent study by Kheirolomom et al. [106], cationic lipoparticles containing anti-miR-712 and coated with VCAM-1 peptide ligand accumulated specifically in inflamed mouse endothelium and effectively prevented atherosclerotic plaque formation in mice.

Apart from small peptide sequences, also monoclonal antibodies against VCAM-1 conjugated to iron oxide microparticles were used to target atherosclerotic lesions of ApoE-deficient mice. These nanoconstructs were capable of detecting activated endothelial cells, and their affinity to the endothelium could be further significantly improved by adding an additional P-selectin-targeting moiety [107]. Collectively, these results indicate that both monoclonal antibodies and small peptide ligands to VCAM-1 can significantly improve endothelial targeting of nanoparticles in vivo and allow disease-dependent particle accumulation even in the large vessels.

Endothelial targeting with nanocarriers conjugated to anti-ICAM and anti-PECAM antibodies under flow conditions was also addressed in detail by the group of Muzykantov [108, 109]. The endocytosis of polystyrene nanoparticles conjugated to anti-ICAM-1 antibodies ( $\sim 180 \mathrm{~nm}$ diameter $)$ was investigated in endothelial-like cells (EAhy926 cells) and primary HUVECs pre-exposed to laminar shear

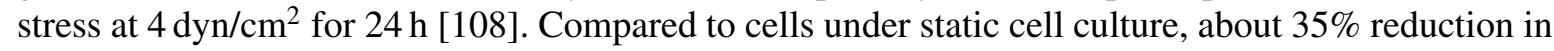
uptake of ICAM-targeted nanoparticles was observed in flow-adapted endothelial cells. Both in static conditions and under flow, the particles were internalized via a non-classical pathway, CAM-mediated endocytosis. The authors concluded that actin recruitment to stress fibers which control the cell shape under flow may delay the uptake of ICAM-targeted nanoparticles by interfering with actin reorganization required for CAM-mediated endocytosis. In vivo, relatively slow, but effective endocytosis of ICAM-targeted nanoparticles was detected in mouse pulmonary endothelium after intravenous injection, which was accelerated by the treatment with LPS. In accordance with the in vitro data and the theoretical predictions, nanoparticle uptake was slightly faster in capillaries with lower shear stress [108].

The impact of acute and chronic flow conditions on the CAM-mediated endothelial internalization of PECAM-targeted nanospheres $(180 \mathrm{~nm})$ was investigated by Han et al. [109]. The formation of actin stress fibers upon flow-adaptation $\left(5 \mathrm{dyn} / \mathrm{cm}^{2}\right.$ for $\left.16 \mathrm{~h}\right)$ inhibited the uptake of anti-PECAM nanoparticles, which was in accordance with the in vivo results showing lower rates of anti-PECAM nanoparticle endocytosis in arterial compared to capillary vessels. Since the acute induction of actin stress fibers in the absence of flow had similar suppressive effect on nanoparticle internalization, whereas acute flow without stress fiber formation $\left(1 \mathrm{dyn} / \mathrm{cm}^{2}\right.$ for $\left.30 \mathrm{~min}\right)$ stimulated the uptake, the authors concluded that the formation of actin stress fibers interferes with endothelial endocytic pathways [109]. In contrast to ICAM-targeted particles, internalization of PECAM-conjugated nanocarriers was not 
induced in activated HUVECs. Unlike ICAM, PECAM is not cytokine-induced, but is abundantly expressed also by quiescent cells and primarily localized to cell-cell junctions. Being involved in shear stress-mediated mechanotransduction [110], PECAM was shown to promote atherosclerotic lesion formation in regions of disturbed flow [80]. It is unknown, however, if the uptake of PECAM-targeted nanocarriers differs between cells exposed to various patterns of shear stress. The above-discussed studies demonstrate that the regulation of targeted-nanoparticle internalization by flow conditions and/or endothelial activation may strongly modulate drug delivery into endothelium exposed to different physiological hemodynamic patterns (capillaries vs. arterioles/arteries) or pathological conditions (e.g. inflammation).

Selectins, rapidly upregulated on endothelial cells upon their activation, constitute another potential target for molecular imaging and drug delivery to endothelium. In a mouse model of inflammation, an anti-E-selectin monoclonal antibody was conjugated to ultrasmall SPION for targeting E-selectin in vivo [111]. Injection of targeted nanoparticles resulted in distinct changes in $\mathrm{R} 2$ relaxation rate (1/T 2) characteristics in inflamed regions as compared with control regions, which were subsequently confirmed by histologic analysis, indicating that the E-selectin-targeted probe detects specific pattern of vascular inflammation [111].

P-selectin is expressed both by platelets and activated endothelium, so the nanoparticles targeted to P-selectin are not specific to activated endothelial cells. However, dual targeting of P-selectin and VCAM-1 with iron oxide microparticles has been successfully employed for MR imaging of atherosclerotic plaques in ApoE-deficient mice [107]. Moreover, several recent studies utilized plateletmimicking approach to nanoparticle functionalization in order to improve endothelial targeting. Lin et al. [112] compared unconjugated polystyrene NPs $(100 \mathrm{~nm})$ with nanoparticles conjugated with glycocalicin, the extracellular fragment of platelet glycoprotein Ib $\alpha$ (GPIb $\alpha$ ), in terms of their uptake by human aortic endothelial cells under physiological flow conditions (shear stress between $0 \mathrm{dyn} / \mathrm{cm}^{2}$ to $15 \mathrm{dyn} / \mathrm{cm}^{2}$ ). Whereas cellular uptake of untargeted nanoparticles after 30 minutes of flow was strongly decreased with the increase of shear stress magnitude, leading to nearly abolished uptake at $15 \mathrm{dyn} / \mathrm{cm}^{2}$, this effect was prevented by the presence of GPIb $\alpha$ on the particles. Compared to static conditions, GPIb $\alpha$-conjugated nanoparticles showed a slightly diminished uptake under $5 \mathrm{dyn} / \mathrm{cm}^{2}$ and a more pronounced reduction of internalization at $15 \mathrm{dyn} / \mathrm{cm}^{2}$, but numbers of internalized particles were only $30 \%$ smaller than in static conditions [112]. In a further study from the same group [113], dexamethasone-loaded PLGA nanoparticles $(220 \mathrm{~nm})$ were conjugated with GPIb $\alpha$ and compared with untargeted nanoparticles under varying levels of shear stress $\left(0-25 \mathrm{dyn} / \mathrm{cm}^{2}\right)$ after 30 minutes of flow. Relative of static conditions, the cell-associated unconjugated particles were decreased by $80 \%$ at $25 \mathrm{dyn} / \mathrm{cm}^{2}$ and localized mostly to extracellular spaces, with minimal accumulation within the cells. On the contrary, GPIb-nanoparticles were strongly internalized by endothelial cells, and their uptake at increasing shear stress levels was significantly higher than that of untargeted particles. Intraarterial infusion of nanoparticles in an ex vivo rat model of carotid balloon injury over 3 minutes demonstrated that 2-fold more GPIb-conjugated nanoparticles adhered to the injured arterial wall, as compared to control particles, indicating that the GPIb-conjugated PLGA nanoparticles can effectively deliver drugs at the site of vascular injury [113].

PLGA particles cloaked in platelet membrane vesicles were also utilized by $\mathrm{Hu}$ et al. [114] as an intravenous docetaxel delivery platform in a rat model of coronary restenosis. The platelet-like functionality of these particles was demonstrated by selective binding to the damaged vasculature in a rat model of angioplasty-induced arterial damage. The platelet-mimicking particles furthermore showed a superb therapeutic efficacy in a rat model of coronary stenosis, as compared with free docetaxel [114]. Collectively, these findings suggest that nanoparticles mimicking the interactions of platelets with activated endothelial cells/subendothelial matrix can bind to the arterial wall under physiologic flow conditions. 


\subsection{Magnetic targeting}

"Magnetic drug targeting" utilizes an external magnetic field to target drugs conjugated with SPIONs to the diseased vasculature regions (Fig. 2B). The efficacy of this approach, both in terms of the amounts of delivered drug and the therapeutic outcome has been demonstrated in several studies on tumorbearing rabbits treated with mitoxantrone-loaded SPIONs applied intraarterially under the guidance of an external magnet [56, 57].

Chao et al. [61] investigated the tumor targeting and therapeutic efficacy of a magnet-enhanced delivery in vivo using PEG-modified iron oxide/gold nanoparticles $(50 \mathrm{~nm})$ loaded with doxorubicin. Upon intravenous administration of doxorubicin-loaded particles to hepatoma cell tumor-bearing mice, a significantly increased accumulation of doxorubicin in tumors was achieved with external magnetic force [61], leading to a significant tumor volume reduction as compared with free drug and nonmagnetically targeted particles.

In a recent report, Elbialy et al. [62] utilized PEG-ylated iron oxide/gold nanoparticles loaded with doxorubicin $(22 \mathrm{~nm})$ for magnetic drug targeting. Compared with passive targeting, a single intravenous application of nanoparticles combined with magnetic targeting provided a higher accumulation of drug in tumor tissue after $24 \mathrm{~h}$ post-application in a mouse model of Ehrlich carcinoma, contributing to subsequent tumor growth inhibition and reduced side effects in healthy tissues [62].

Effective site-specific magnetic targeting of intravenously-administered nanoparticles by placing a magnet above the tumor in mice was also shown by Yu et al. [63], who employed carbon-coated iron carbide $\left(\mathrm{Fe}_{5} \mathrm{C}_{2}\right)$ nanoparticles functionalized with bovine serum albumin and loaded with doxorubicin. The above-described studies indicate that active targeting using the magnetic field enhances the specific drug delivery to the tumor vasculature and increases its therapeutic efficacy.

Magnetic targeting was furthermore effective in a rat model of myocardial infarction reported by Zhang et al. [60], where the externally-controlled magnetic nanobeads conjugated to adenoviral vectors-encoded human VEGF gene were administered intravenously. The external epicardial magnetenhanced targeting resulted in a strong VEGF gene expression in the ischemic region and improved cardiac repair [60]. It must be noted, however, that thus far the experimental attempts to magnetically target the larger arteries have been relatively scarce (e.g. rat iliac artery embolic model [59], rat femoral artery [115], large arteries and smaller arterial branches in primates [23]), although ex vivo studies indicate that accumulation of flowing SPIONs in the arterial wall is easily achievable under the guidance of a sufficiently strong external magnet.

\section{Conclusions and perspectives}

Nanotechnology-based strategies are expected to have a great clinical impact on the diagnostics and therapy of human diseases in the future. To ensure the clinical safety and feasibility of these entirely novel approaches, a rational design of nanoparticulate contrast agents and drug carriers is necessary. Ideally, the parenterally-administered particles should be able to achieve an increased circulation half-life and a high margination rate, and allow enhanced interactions with endothelial cells in the target region. Passive targeting can be used to deliver nanotherapeutics to the diseased regions, but its efficacy is limited to the vascular beds where the blood-tissue barrier is compromised. In arterial circulation, shear stress-activated processes may significantly affect the nanoparticle internalization by endothelial cells. Therefore, several targeting strategies are employed to ensure the delivery of a sufficient payload of drug to the vascular regions under physiologic shear stress conditions, whereby the most promising experimental results have thus far been reported with endothelial adhesion molecule-targeting and magnetic drug targeting approaches. Further studies in vitro 
and in vivo are necessary to determine the key factors affecting particle internalization under flow conditions.

\section{Acknowledgments}

This work was supported by the DFG (CI 162/2-1) and the EU "NanoAthero" project FP7-NMP2012-LARGE-6-309820.

\section{References}

[1] Alexis F, Pridgen E, Molnar LK, Farokhzad OC. Factors affecting the clearance and biodistribution of polymeric nanoparticles. Molecular pharmaceutics 2008;5:505-15.

[2] Chen B, Pogue BW, Hoopes PJ, Hasan T. Vascular and cellular targeting for photodynamic therapy. Critical Reviews in Eukaryotic Gene Expression 2006;16:279-305.

[3] Kennel SJ, Woodward JD, Rondinone AJ, Wall J, Huang Y, Mirzadeh S. The fate of MAb-targeted Cd(125m)Te/ZnS nanoparticles in vivo. Nuclear medicine and biology 2008;35:501-14.

[4] Moros M, Mitchell SG, Grazu V, de la Fuente JM. The Fate of Nanocarriers As Nanomedicines In Vivo: Important Considerations and Biological Barriers to Overcome. Curr Med Chem 2013;20:2759-78.

[5] Sharma A, Madhunapantula SV, Robertson GP. Toxicological considerations when creating nanoparticle-based drugs and drug delivery systems. Expert Opinion on Drug Metabolism \& Toxicology 2012;8:47-69.

[6] Puri A, Loomis K, Smith B, Lee JH, Yavlovich A, Heldman E, Blumenthal R. Lipid-based nanoparticles as pharmaceutical drug carriers: From concepts to clinic. Critical Reviews in Therapeutic Drug Carrier Systems 2009;26:523-80.

[7] Balazs DA, Godbey W. Liposomes for use in gene delivery. Journal of Drug Delivery 2011;326497.

[8] van der Meel R, Vehmeijer LJ, Kok RJ, Storm G, van Gaal EV. Ligand-targeted particulate nanomedicines undergoing clinical evaluation: Current status. Adv Drug Deliv Rev 2013;65:1284-98.

[9] Huwyler J, Drewe J, Krahenbuhl S. Tumor targeting using liposomal antineoplastic drugs. International journal of nanomedicine 2008;3:21-9.

[10] Barenholz Y. Doxil (R) - The first FDA-approved nano-drug: Lessons learned. Journal of Controlled Release 2012;160:117-34.

[11] Danhier F, Ansorena E, Silva JM, Coco R, Le Breton A, Preat V. PLGA-based nanoparticles: An overview of biomedical applications. Journal of Controlled Release : Official Journal of the Controlled Release Society 2012;161:505-22.

[12] Korin N, Kanapathipillai M, Matthews BD, Crescente M, Brill A, Mammoto T, Ghosh K, Jurek S, Bencherif SA, Bhatta D, Coskun AU, Feldman CL, Wagner DD, Ingber DE. Shear-activated nanotherapeutics for drug targeting to obstructed blood vessels. Science 2012;337:738-42.

[13] Nagaoka K, Matoba T, Mao Y, Nakano Y, Ikeda G, Egusa S, Tokutome M, Nagahama R, Nakano K, Sunagawa K, Egashira K. A New Therapeutic Modality for Acute Myocardial Infarction: Nanoparticle-Mediated Delivery of Pitavastatin Induces Cardioprotection from Ischemia-Reperfusion Injury via Activation of PI3K/Akt Pathway and Anti-Inflammation in a Rat Model. PloS one 2015;10:e0132451.

[14] Yun X, Maximov VD, Yu J, Zhu H, Vertegel AA, Kindy MS. Nanoparticles for targeted delivery of antioxidant enzymes to the brain after cerebral ischemia and reperfusion injury. Journal of Cerebral Blood Flow and Metabolism : Official Journal of the International Society of Cerebral Blood Flow and Metabolism 2013;33:583-92.

[15] Geary SM, Salem AK. Exploiting the tumor phenotype using biodegradable submicron carriers of chemotherapeutic drugs. Critical Reviews in Oncogenesis 2014;19:269-80.

[16] Menon JU, Jadeja P, Tambe P, Vu K, Yuan B, Nguyen KT. Nanomaterials for photo-based diagnostic and therapeutic applications. Theranostics 2013;3:152-66.

[17] Zhang X, Teodoro JG, Nadeau JL. Intratumoral gold-doxorubicin is effective in treating melanoma in mice. Nanomedicine : Nanotechnology Biology and Medicine 2015;11:1365-75.

[18] Cheng Y, Dai Q, Morshed RA, Fan X, Wegscheid ML, Wainwright DA, Han Y, Zhang L, Auffinger B, Tobias AL, Rincon E, Thaci B, Ahmed AU, Warnke PC, He C, Lesniak MS. Blood-brain barrier permeable gold nanoparticles: An efficient delivery platform for enhanced malignant glioma therapy and imaging. Small 2014;10:5137-50.

[19] Kudgus RA, Szabolcs A, Khan JA, Walden CA, Reid JM, Robertson JD, Bhattacharya R, Mukherjee P. Inhibiting the growth of pancreatic adenocarcinoma in vitro and in vivo through targeted treatment with designer gold nanotherapeutics. PloS One 2013;8:e57522. 
[20] Spivak MY, Bubnov RV, Yemets IM, Lazarenko LM, Tymoshok NO, Ulberg ZR. Development and testing of gold nanoparticles for drug delivery and treatment of heart failure: A theranostic potential for PPP cardiology. The EPMA Journal 2013;4:20.

[21] Wahajuddin, Arora S. Superparamagnetic iron oxide nanoparticles: Magnetic nanoplatforms as drug carriers. International Journal of Nanomedicine 2012;7:3445-71.

[22] Tassa C, Shaw SY, Weissleder R. Dextran-coated iron oxide nanoparticles: A versatile platform for targeted molecular imaging, molecular diagnostics, and therapy. Accounts of Chemical Research 2011;44:842-52.

[23] Chen HT, Kaminski MD, Pytel P, MacDonald L, Rosengart AJ. Capture of magnetic carriers within large arteries using external magnetic fields. Journal of Drug Targeting 2008;16:262-68.

[24] Hayashi K, Nakamura M, Sakamoto W, Yogo T, Miki H, Ozaki S, Abe M, Matsumoto T, Ishimura K. Superparamagnetic nanoparticle clusters for cancer theranostics combining magnetic resonance imaging and hyperthermia treatment. Theranostics 2013;3:366-376.

[25] Trivedi RA, Mallawarachi C, U-King-Im JM, Graves MJ, Horsley J, Goddard MJ, Brown A, Wang L, Kirkpatrick PJ, Brown J, Gillard JH. Identifying inflamed carotid plaques using in vivo USPIO-enhanced MR imaging to label plaque macrophages. Arteriosclerosis Thrombosis and Vascular Biology 2006;26:1601-06.

[26] Tang TY, Muller KH, Graves MJ, Li ZY, Walsh SR, Young V, Sadat U, Howarth SP, Gillard JH. Iron oxide particles for atheroma imaging. Arteriosclerosis Thrombosis and Vascular Biology 2009;29:1001-08.

[27] Sadat U, Howarth SP, Usman A, Tang TY, Graves MJ, Gillard JH. Sequential Imaging of Asymptomatic Carotid Atheroma Using Ultrasmall Superparamagnetic Iron Oxide-enhanced Magnetic Resonance Imaging: A Feasibility Study. Journal of Stroke and Cerebrovascular Diseases : The Official Journal of National Stroke Association 2013;22:e271-76.

[28] Howarth SP, Tang TY, Trivedi R, Weerakkody R, U-King-Im J, Gaunt ME, Boyle JR, Li ZY, Miller SR, Graves MJ, Gillard JH. Utility of USPIO-enhanced MR imaging to identify inflammation and the fibrous cap: A comparison of symptomatic and asymptomatic individuals. European Journal of Radiology 2009;70:555-60.

[29] Liu DF, Qian C, An YL, Chang D, Ju SH, Teng GJ. Magnetic resonance imaging of post-ischemic blood-brain barrier damage with PEGylated iron oxide nanoparticles. Nanoscale 2014;6:15161-7.

[30] Reddy GR, Bhojani MS, McConville P, Moody J, Moffat BA, Hall DE, Kim G, Koo YE, Woolliscroft MJ, Sugai JV, Johnson TD, Philbert MA, Kopelman R. Rehemtulla A and Ross BD, Vascular targeted nanoparticles for imaging and treatment of brain tumors. Clinical Cancer Research : An Official Journal of the American Association for Cancer Research 2006;12:6677-86.

[31] Tadayon A, Jamshidi R, Esmaeili A. Delivery of tissue plasminogen activator and streptokinase magnetic nanoparticles to target vascular diseases. International Journal of Pharmaceutics 2015;495:428-38.

[32] Wolinsky H. A proposal linking clearance of circulating lipoproteins to tissue metabolic activity as a basis for understanding atherogenesis. Circulation Research 1980;47:301-11.

[33] Urschel K, Cicha I. TNF- $\alpha$ in the cardiovascular system: From physiology to therapy. International Journal of Interferon Cytokine and Mediator Research 2015;7:9-25.

[34] MacNeil S. Biomaterials for tissue engineering of skin. Mater Today 2008;11:26-35.

[35] Carmeliet P, Jain RK. Angiogenesis in cancer and other diseases. Nature 2000;407:249-57.

[36] Li B, Xiu R. Angiogenesis: From molecular mechanisms to translational implications. Clinical Hemorheology and Microcirculation 2013;54:345-55.

[37] Sluimer JC, Kolodgie FD, Bijnens APJJ, Maxfield K, Pacheco E, Kutys B, Duimel H, Frederik PM, van Hinsbergh VWM, Virmani R, Daemen MJAP. Thin-Walled Microvessels in Human Coronary Atherosclerotic Plaques Show Incomplete Endothelial Junctions Relevance of Compromised Structural Integrity for Intraplaque Microvascular Leakage. Journal of the American College of Cardiology 2009;53:1517-27.

[38] Virmani R, Kolodgie FD, Burke AP, Finn AV, Gold HK, Tulenko TN, Wrenn SP, Narula J. Atherosclerotic plaque progression and vulnerability to rupture - Angiogenesis as a source of intraplaque hemorrhage. Arterioscl Throm Vas 2005;25:2054-61.

[39] Le Dall J, Ho-Tin-Noe B, Louedec L, Meilhac O, Roncal C, Carmeliet P, Germain S, Michel JB, Houard X. Immaturity of microvessels in haemorrhagic plaques is associated with proteolytic degradation of angiogenic factors. Cardiovascular Research 2010;85:184-93.

[40] Shubik P. Vascularization of Tumors - a Review. J Cancer Res Clin 1982;103:211-26.

[41] Hobbs SK, Monsky WL, Yuan F, Roberts WG, Griffith L, Torchilin VP, Jain RK. Regulation of transport pathways in tumor vessels: Role of tumor type and microenvironment. Proceedings of the National Academy of Sciences of the United States of America 1998;95:4607-12.

[42] Feng D, Nagy JA, Dvorak HF, Dvorak AM. Ultrastructural studies define soluble macromolecular, particulate, and cellular transendothelial cell pathways in venules, lymphatic vessels, and tumor-associated microvessels in man and animals. Microscopy Research and Technique 2002;57:289-326. 
[43] Haley B, Frenkel E. Nanoparticles for drug delivery in cancer treatment. Urol Oncol-Semin Ori 2008;26:57-64.

[44] Byrne JD, Betancourt T, Brannon-Peppas L. Active targeting schemes for nanoparticle systems in cancer therapeutics. Adv Drug Deliver Rev 2008;60:1615-26.

[45] Greish K. Enhanced permeability and retention (EPR) effect for anticancer nanomedicine drug targeting. Methods in Molecular Biology 2010;624:25-37.

[46] Xu F, Lu W, Wu H, Fan L, Gao X, Jiang X. Brain delivery and systemic effect of cationic albumin conjugated PLGA nanoparticles. Journal of Drug Targeting 2009;17:423-34.

[47] Ran S, Downes A, Thorpe PE. Increased exposure of anionic phospholipids on the surface of tumor blood vessels. Cancer Res 2002;62:6132-40.

[48] Thurston G, McLean JW, Rizen M, Baluk P, Haskell A, Murphy TJ, Hanahan D, McDonald DM. Cationic liposomes target angiogenic endothelial cells in tumors and chronic inflammation in mice. J Clin Invest 1998;101:1401-13.

[49] Krasnici S, Werner A, Eichhorn ME, Schmitt-Sody M, Pahernik SA, Sauer B, Schulze B, Teifel M, Michaelis U, Naujoks K, Dellian M. Effect of the surface charge of liposomes on their uptake by angiogenic tumor vessels. Int J Cancer 2003;105:561-67.

[50] Leupold E, Nikolenko H, Dathe M. Apolipoprotein E peptide-modified colloidal carriers: The design determines the mechanism of uptake in vascular endothelial cells. Bba-Biomembranes 2009;1788:442-9.

[51] Backer MV, Gaynutdinov TI, Patel V, Bandyopadhyaya AK, Thirumamagal BT, Tjarks W, Barth RF, Claffey K, Backer JM. Vascular endothelial growth factor selectively targets boronated dendrimers to tumor vasculature. Molecular Cancer Therapeutics 2005;4:1423-9.

[52] Shi SX, Yang K, Hong H, Chen F, Valdovinos HF, Goel S, Barnhart TE, Liu Z, Cai WB. VEGFR targeting leads to significantly enhanced tumor uptake of nanographene oxide in vivo. Biomaterials 2015;39:39-46.

[53] Graf N, Bielenberg DR, Kolishetti N, Muus C, Banyard J, Farokhzad OC, Lippard SJ. alpha(V)beta(3) integrin-targeted PLGA-PEG nanoparticles for enhanced anti-tumor efficacy of a Pt(IV) prodrug. ACS Nano 2012;6:4530-9.

[54] Eldar-Boock A, Miller K, Sanchis J, Lupu R, Vicent MJ, Satchi-Fainaro R. Integrin-assisted drug delivery of nanoscaled polymer therapeutics bearing paclitaxel. Biomaterials 2011;32:3862-74.

[55] Simone E, Ding BS, Muzykantov V. Targeted delivery of therapeutics to endothelium. Cell and Tissue Research 2009;335: 283-300.

[56] Lyer S, Tietze R, Jurgons R, Struffert T, Engelhorn T, Schreiber E, Dorfler A, Alexiou C. Visualisation of tumour regression after local chemotherapy with magnetic nanoparticles - a pilot study. Anticancer Research 2010;30: 1553-7.

[57] Tietze R, Lyer S, Durr S, Struffert T, Engelhorn T, Schwarz M, Eckert E, Goen T, Vasylyev S, Peukert W, Wiekhorst F, Trahms L, Dorfler A, Alexiou C. Efficient drug-delivery using magnetic nanoparticles-biodistribution and therapeutic effects in tumour bearing rabbits. Nanomedicine : Nanotechnology Biology and Medicine 2013;9:961-71.

[58] Janko C, Durr S, Munoz LE, Lyer S, Chaurio R, Tietze R, Lohneysen S, Schorn C, Herrmann M, Alexiou C. Magnetic drug targeting reduces the chemotherapeutic burden on circulating leukocytes. International Journal of Molecular Sciences 2013;14:7341-55.

[59] Ma YH, Wu SY, Wu T, Chang YJ, Hua MY, Chen JP. Magnetically targeted thrombolysis with recombinant tissue plasminogen activator bound to polyacrylic acid-coated nanoparticles. Biomaterials 2009;30:3343-51.

[60] Zhang Y, Li W, Ou L, Wang W, Delyagina E, Lux C, Sorg H, Riehemann K, Steinhoff G, Ma N. Targeted delivery of human VEGF gene via complexes of magnetic nanoparticle-adenoviral vectors enhanced cardiac regeneration. PloS one 2012;7:e39490.

[61] Chao X, Zhang ZL, Guo LL, Zhu JJ, Peng ML, Vermorken AJM, Van de Ven WJM, Chen C, Cui YL. A Novel Magnetic Nanoparticle Drug Carrier for Enhanced Cancer Chemotherapy. PloS one 2012;7.

[62] Elbialy NS, Fathy MM, Khalil WM. Doxorubicin loaded magnetic gold nanoparticles for in vivo targeted drug delivery. International Journal of Pharmaceutics 2015;490:190-9.

[63] Yu J, Ju Y, Zhao L, Chu X, Yang W, Tian Y, Sheng F, Lin J, Liu F, Dong Y, Hou Y. Multistimuli-Regulated Photochemothermal Cancer Therapy Remotely Controlled via FeC Nanoparticles. ACS Nano 2015.

[64] Wu SP, Ringgaard S, Oyre S, Hansen MS, Rasmus S, Pedersen EM. Wall shear rates differ between the normal carotid, femoral, and brachial arteries: An in vivo MRI study. J Magn Reson Imaging 2004;19:188-93.

[65] Secomb TW. Red-Blood-Cell Mechanics and Capillary Blood Rheology. Cell Biophys 1991;18:231-51.

[66] Wischke C, Kruger A, Roch T, Pierce BF, Li W, Jung F, Lendlein A. Endothelial cell response to (co)polymer nanoparticles depending on the inflammatory environment and comonomer ratio. European Journal of Pharmaceutics and Biopharmaceutics : Official Journal of Arbeitsgemeinschaft fur Pharmazeutische Verfahrenstechnik e.V 2013;84:288-296.

[67] Chatzizisis YS, Coskun AU, Jonas M, Edelman ER, Feldman CL, Stone PH. Role of endothelial shear stress in the natural history of coronary atherosclerosis and vascular remodeling - Molecular, cellular, and vascular behavior. J Am Coll Cardiol 2007;49:2379-93. 
[68] Li YSJ, Haga JH, Chien S. Molecular basis of the effects of shear stress on vascular endothelial cells. J Biomech 2005;38:1949-71.

[69] Dimmeler S, Haendeler J, Rippmann V, Nehls M, Zeiher AM. Shear stress inhibits apoptosis of human endothelial cells. FEBS Letters 1996;399:71-4.

[70] Hoffmann J, Haendeler J, Aicher A, Rossig L, Vasa M, Zeiher AM, Dimmeler S. Aging enhances the sensitivity of endothelial cells toward apoptotic stimuli: Important role of nitric oxide. Circulation Research 2001;89: 709-15.

[71] Dimmeler S, Hermann C, Galle J, Zeiher AM. Upregulation of superoxide dismutase and nitric oxide synthase mediates the apoptosis-suppressive effects of shear stress on endothelial cells. Arteriosclerosis Thrombosis and Vascular Biology 1999;19:656-64.

[72] Yamawaki H, Lehoux S, Berk BC. Chronic physiological shear stress inhibits tumor necrosis factor-induced proinflammatory responses in rabbit aorta perfused ex vivo. Circulation 2003;108:1619-25.

[73] Partridge J, Carlsen H, Enesa K, Chaudhury H, Zakkar M, Luong L, Kinderlerer A, Johns M, Blomhoff R, Mason JC, Haskard DO, Evans PC. Laminar shear stress acts as a switch to regulate divergent functions of NF-kappaB in endothelial cells. FASEB Journal : Official Publication of the Federation of American Societies for Experimental Biology 2007;21:3553-61.

[74] Cicha I, Beronov K, Ramirez EL, Osterode K, Goppelt-Struebe M, Raaz D, Yilmaz A, Daniel WG, Garlichs CD. Shear stress preconditioning modulates endothelial susceptibility to circulating TNF-alpha and monocytic cell recruitment in a simplified model of arterial bifurcations. Atherosclerosis 2009;207:93-102.

[75] Haldenby KA, Chappell DC, Winlove CP, Parker KH, Firth JA. Focal and regional variations in the composition of the glycocalyx of large vessel endothelium. Journal of Vascular Research 1994;31:2-9.

[76] van den Berg BM, Spaan JA, Rolf TM, Vink H. Atherogenic region and diet diminish glycocalyx dimension and increase intima-to-media ratios at murine carotid artery bifurcation. American journal of physiology. Heart and Circulatory Physiology 2006;290:H915-20.

[77] Koo A, Dewey CF Jr., Garcia-Cardena G, Hemodynamic shear stress characteristic of atherosclerosis-resistant regions promotes glycocalyx formation in cultured endothelial cells. American journal of physiology. Cell Physiology 2013;304:C137-46.

[78] Oberleithner H, Peters W, Kusche-Vihrog K, Korte S, Schillers H, Kliche K, Oberleithner K. Salt overload damages the glycocalyx sodium barrier of vascular endothelium. Pflugers Archiv : European Journal of Physiology 2011;462: 519-28.

[79] Korte S, Wiesinger A, Straeter AS, Peters W, Oberleithner H, Kusche-Vihrog K. Firewall function of the endothelial glycocalyx in the regulation of sodium homeostasis. Pflugers Archiv : European Journal of Physiology 2012;463: 269-78.

[80] Harry BL, Sanders JM, Feaver RE, Lansey M, Deem TL, Zarbock A, Bruce AC, Pryor AW, Gelfand BD, Blackman BR, Schwartz MA, Ley K. Endothelial cell PECAM-1 promotes atherosclerotic lesions in areas of disturbed flow in ApoE-deficient mice. Arteriosclerosis Thrombosis and Vascular Biology 2008;28:2003-8.

[81] Hajra L, Evans AI, Chen M, Hyduk SJ, Collins T, Cybulsky MI. The NF-kappa B signal transduction pathway in aortic endothelial cells is primed for activation in regions predisposed to atherosclerotic lesion formation. Proceedings of the National Academy of Sciences of the United States of America 2000;97:9052-7.

[82] Zakkar M, Chaudhury H, Sandvik G, Enesa K, Luong le A, Cuhlmann S, Mason JC, Krams R, Clark AR, Haskard DO, Evans PC. Increased endothelial mitogen-activated protein kinase phosphatase-1 expression suppresses proinflammatory activation at sites that are resistant to atherosclerosis. Circulation Research 2008;103:726-32.

[83] Chappell D, Hofmann-Kiefer K, Jacob M, Rehm M, Briegel J, Welsch U, Conzen P, Becker BF. TNF-alpha induced shedding of the endothelial glycocalyx is prevented by hydrocortisone and antithrombin. Basic Research in Cardiology 2009; $104: 78-89$.

[84] Devendran T, Brandhuber M, Schmid-Schonbein H. Axial migration of RBC and the influence of cell flexibility and aggregation. Bibliotheca Anatomica 1975;13:95-6.

[85] Ku DN. Blood flow in arteries. Annu Rev Fluid Mech 1997;29:399-434.

[86] Kim S, Kong RL, Popel AS, Intaglietta M, Johnson PC. Temporal and spatial variations of cell-free layer width in arterioles. American journal of physiology. Heart and Circulatory Physiology 2007;293:H1526-35.

[87] Muller K, Fedosov DA, Gompper G. Understanding particle margination in blood flow - A step toward optimized drug delivery systems. Medical Engineering \& physics (2015).

[88] Samuel SP, Jain N, O’Dowd F, Paul T, Kashanin D, Gerard VA, Gun'ko YK, Prina-Mello A, Volkov Y. Multifactorial determinants that govern nanoparticle uptake by human endothelial cells under flow. International Journal of Nanomedicine 2012;7:2943-56.

[89] Satcher R, Dewey CF, Hartwig JH. Mechanical remodeling of the endothelial surface and actin cytoskeleton induced by fluid flow. Microcirculation-Lon 1997;4:439-53. 
[90] Wojciak-Stothard B, Ridley AJ. Shear stress-induced endothelial cell polarization is mediated by Rho and Rac but not Cdc42 or PI 3-kinases. J Cell Biol 2003;161:429-39.

[91] Noria S, Xu F, McCue S, Jones M, Gotlieb AI, Langille BL. Assembly and reorientation of stress fibers drives morphological changes to endothelial cells exposed to shear stress. Am J Pathol 2004;164:1211-23.

[92] Rinkenauer AC, Press AT, Raasch M, Pietsch C, Schweizer S, Schworer S, Rudolph KL, Mosig A, Bauer M, Traeger A, Schubert US. Comparison of the uptake of methacrylate-based nanoparticles in static and dynamic in vitro systems as well as in vivo. Journal of Controlled Release 2015;216:158-168.

[93] Fede C, Fortunati I, Weber V, Rossetto N, Bertasi F, Petrelli L, Guidolin D, Signorini R, De Caro R, Albertin G, Ferrante C. Evaluation of gold nanoparticles toxicity towards human endothelial cells under static and flow conditions. Microvasc Res 2015;97:147-155.

[94] Matuszak J, Baumgartner J, Zaloga J, Juenet M, Eduardo da Silva A, Franke D, Almer G, Texier I, Faivre D, Metselaar JM, Navarro FP, Chauvierre C, Prassl R, Dézsi L, Urbanics R, Alexiou C, Mangge H, Szebeni J, Letourneur D, Cicha I. Nanoparticles for intravascular applications: Physicochemical characterization and cytotoxicity testing. Nanomedicine (Lond.) in press (2016).

[95] Aarts PA, van den Broek SA, Prins GW, Kuiken GD, Sixma JJ, Heethaar RM. Blood platelets are concentrated near the wall and red blood cells, in the center in flowing blood. Arteriosclerosis 1988;8:819-824.

[96] Blackshear PL, Jr., Forstrom RJ, Dorman FD, Voss GO. Effect of flow on cells near walls. Federation Proceedings 1971;30:1600-11.

[97] Eckstein EC, Tilles AW, Millero FJ. 3rd, Conditions for the occurrence of large near-wall excesses of small particles during blood flow. Microvasc Res 1988;36:31-39.

[98] Lee SY, Ferrari M, Decuzzi P. Shaping nano-/micro-particles for enhanced vascular interaction in laminar flows. Nanotechnology 2009;20.

[99] Charoenphol P, Huang RB, Eniola-Adefeso O. Potential role of size and hemodynamics in the efficacy of vasculartargeted spherical drug carriers. Biomaterials 2010;31:1392-1402.

[100] Thompson AJ, Mastria EM, Eniola-Adefeso O. The margination propensity of ellipsoidal micro/nanoparticles to the endothelium in human blood flow. Biomaterials 2013;34:5863-71.

[101] Carboni E, Tschudi K, Nam J, Lu XL, Ma AWK, Particle Margination and Its Implications on Intravenous Anticancer Drug Delivery. Aaps Pharmscitech 2014;15:762-71.

[102] Yang H, Xiong X, Zhang L, Wu C, Liu Y. Adhesion of bio-functionalized ultrasound microbubbles to endothelial cells by targeting to vascular cell adhesion molecule-1 under shear flow. International Journal of Nanomedicine 2011;6:2043-51.

[103] Yang H, Zhao F, Li Y, Xu M, Li L, Wu C, Miyoshi H, Liu Y. VCAM-1-targeted core/shell nanoparticles for selective adhesion and delivery to endothelial cells with lipopolysaccharide-induced inflammation under shear flow and cellular magnetic resonance imaging in vitro. International Journal of Nanomedicine 2013;8:1897-1906.

[104] Kelly KA, Allport JR, Tsourkas A, Shinde-Patil VR, Josephson L, Weissleder R, Detection of vascular adhesion molecule-1 expression using a novel multimodal nanoparticle. Circulation Research 2005;96:327-36.

[105] Nahrendorf M, Jaffer FA, Kelly KA, Sosnovik DE, Aikawa E, Libby P, Weissleder R. Noninvasive vascular cell adhesion molecule-1 imaging identifies inflammatory activation of cells in atherosclerosis. Circulation 2006;114: 1504-11.

[106] Kheirolomoom A, Kim CW, Seo JW, Kumar S, Son DJ, Gagnon MK, Ingham ES, Ferrara KW, Jo H. Multifunctional Nanoparticles Facilitate Molecular Targeting and miRNA Delivery to Inhibit Atherosclerosis in ApoE(-/-) Mice. ACS Nano 2015;9:8885-97.

[107] McAteer MA, Schneider JE, Ali ZA, Warrick N, Bursill CA, von zur Muhlen C, Greaves DR, Neubauer S, Channon KM, Choudhury RP. Magnetic resonance imaging of endothelial adhesion molecules in mouse atherosclerosis using dual-targeted microparticles of iron oxide. Arteriosclerosis Thrombosis and Vascular Biology 2008;28: 77-83.

[108] Bhowmick T, Berk E, Cui X, Muzykantov VR, Muro S. Effect of flow on endothelial endocytosis of nanocarriers targeted to ICAM-1. Journal of Controlled Release : Official Journal of the Controlled Release Society 2012;157:48592.

[109] Han J, Zern BJ, Shuvaev VV, Davies PF, Muro S, Muzykantov V. Acute and chronic shear stress differently regulate endothelial internalization of nanocarriers targeted to platelet-endothelial cell adhesion molecule-1. ACS Nano 2012;6:8824-36.

[110] Tzima E, Irani-Tehrani M, Kiosses WB, Dejana E, Schultz DA, Engelhardt B, Cao GY, DeLisser H, Schwartz MA. A mechanosensory complex that mediates the endothelial cell response to fluid shear stress. Nature 2005;437: 426-31.

[111] Reynolds PR, Larkman DJ, Haskard DO, Hajnal JV, Kennea NL, George AJ, Edwards AD. Detection of vascular expression of E-selectin in vivo with MR imaging. Radiology 2006;241:469-76. 
[112] Lin A, Sabnis A, Kona S, Nattama S, Patel H, Dong JF, Nguyen KT. Shear-regulated uptake of nanoparticles by endothelial cells and development of endothelial-targeting nanoparticles. Journal of Biomedical Materials Research Part A 2010;93A:833-42.

[113] Kona S, Dong JF, Liu YL, Tan JF, Nguyen KT. Biodegradable nanoparticles mimicking platelet binding as a targeted and controlled drug delivery system. International Journal of Pharmaceutics 2012;423:516-24.

[114] Hu CM, Fang RH, Wang KC, Luk BT, Thamphiwatana S, Dehaini D, Nguyen P, Angsantikul P, Wen CH, Kroll AV, Carpenter C, Ramesh M, Qu V, Patel SH, Zhu J, Shi W, Hofman FM, Chen TC, Gao W, Zhang K, Chien S, Zhang L. Nanoparticle biointerfacing by platelet membrane cloaking. Nature 2015;526:118-21.

[115] Ma HL, Qi XR, Ding WX, Maitani Y, Nagai T. Magnetic targeting after femoral artery administration and biocompatibility assessment of superparamagnetic iron oxide nanoparticles. Journal of biomedical materials research. Part A 2008;84:598-606. 